This item was submitted to Loughborough's Research Repository by the author.

Items in Figshare are protected by copyright, with all rights reserved, unless otherwise indicated.

\title{
Lesson study in mathematics initial teacher education in England
}

PLEASE CITE THE PUBLISHED VERSION

https://www.springer.com/gb/book/9783030040307

\section{PUBLISHER}

Springer International Publishing @ Springer Nature

\section{VERSION}

AM (Accepted Manuscript)

\section{PUBLISHER STATEMENT}

This is a pre-copyedited version of a contribution published in Huang, R., Takahashi, A. and da Ponte, J.P. (eds). Theory and Practice of Lesson Study in Mathematics: An International Perspective published by Springer. The definitive authenticated version is available online via https://doi.org/10.1007/978-3-030-04031-4

\section{LICENCE}

CC BY-NC-ND 4.0

\section{REPOSITORY RECORD}

Baldry, Fay, and Colin Foster. 2019. "Lesson Study in Mathematics Initial Teacher Education in England". Loughborough University. https://hdl.handle.net/2134/37711. 


\title{
Lesson Study in Mathematics Initial Teacher Education in England
}

\section{Fay Baldry* and Colin Foster}

\author{
F. Baldry \\ School of Education, University of Leicester, 21 University Road, \\ Leicester LE1 7RF, UK \\ Email: fb128@le.ac.uk; Tel: (44) 01162523671 \\ C. Foster \\ School of Education, University of Leicester, 21 University Road, \\ Leicester LE1 7RF, UK \\ Email: colin.foster@leicester.ac.uk; Tel: (44) 01162297519
}

\begin{abstract}
Drawing on research in mathematics initial teacher education (ITE) in England, this chapter explores the potential of lesson study to support pre-service mathematics teachers' pedagogical development. We draw attention to ways in which lesson study can be highly transformative of beginning mathematics teachers' pedagogical learning. We consider the current ITE context in England and analyse potential opportunities and challenges for incorporating lesson study into mathematics ITE courses. We conclude by proposing a theoretical model for using lesson study in mathematics ITE that takes account of these contextual issues and offers ways to make the most of the opportunities available. We particularly highlight the importance of a productive partnership between university and school, the need to focus both collaborative lesson planning and observation on a clear research question that relates to student learning of mathematics, and the necessity of a tight protocol for post-lesson discussions.
\end{abstract}

Keywords Initial teacher education. Lesson study. Mathematics education. School partnerships.

\section{Introduction}

In recent years, several variants of lesson study (Fernandez and Yoshida 2012) have been deployed in mathematics initial teacher education (ITE) courses in England (e.g. Archer 2016). The adoption of lesson study outside of Japan has brought a diversification of 
approaches, but all generally involve a cycle of collaborative planning, an observed research lesson and some form of post-lesson discussion, similar to the model described by Cajkler and Wood (2016a, see figure 1). The patterns followed in mathematics lesson study in ITE in England have been shaped by the particular features of the ITE context here, which present challenges to the implementation of lesson study but also potentially offer considerable opportunities to support pre-service teachers' pedagogical development. In this chapter, we survey key aspects of approaches to mathematics ITE lesson study that could increase the likelihood of its success.

We summarise these in a proposed theoretical model for using mathematics lesson study with pre-service teachers.

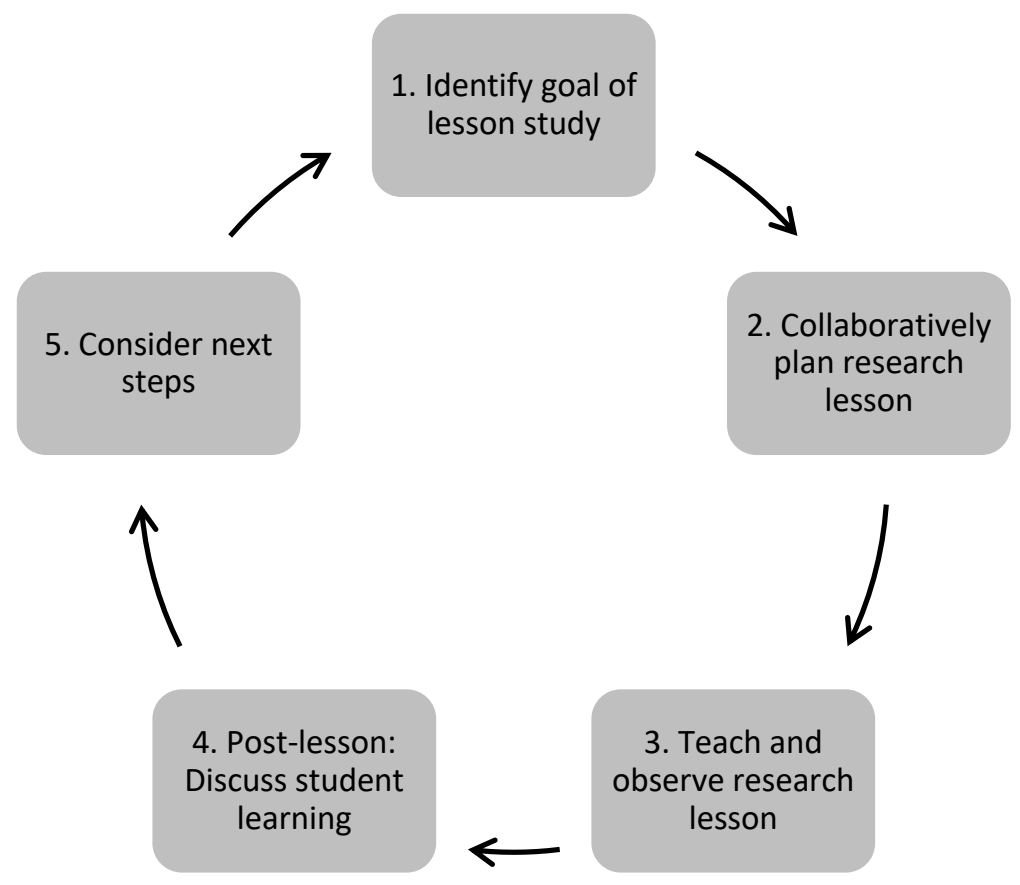

Fig. 1 A cycle of lesson study. (Adapted from Cajkler and Wood 2016a, p. 2)

Currently, ITE provision in England is heavily fragmented, with trends moving away from university-led provision and towards an emphasis on school-led pathways. Pre-service teachers now choose from a range of different routes, which are typically a one-year 
postgraduate programme but with variations in their levels of higher education institution (HEI) involvement. The shift towards schoolled routes has had wider effects on the power relationships between schools and HEIs, meaning that expertise in teacher education may be seen to reside primarily in the school, or in the HEI, or be distributed across some combination of the two. This has implications for mathematics lesson study in ITE, where the school may take a central or a more peripheral role in the process. For example, if a 'knowledgeable other' (KO) role is included in the lesson study model, then this might be provided by the HEI, if that is where the relevant expertise is considered to lie. Alternatively, this role could be taken by a senior leader in the school or by another individual regarded as having the appropriate pedagogical expertise, either within the school or from another school.

In this chapter, we outline what we see as key features of mathematics lesson study in ITE that should be carefully considered within the context in England. We draw these together to offer a research-informed theoretical model for lesson study in mathematics ITE (figure 2), based on ways in which lesson study has been shown to be successful. We argue that this model is realistic and has considerable potential to support pre-service teachers' pedagogical development.

\section{Lesson study in mathematics ITE}

Lesson study is a powerful model for professional development. In Japan, pre-service mathematics teachers typically attend multiple lesson-study events during their ITE, and may also sometimes teach research lesson themselves. However, when lesson study has been adapted for use in ITE in other parts of the world, it has become common for pre-service teachers both to observe and to teach the research lessons, and this may indeed be seen as central to the process (Larssen et al. 2018). In England, while the composition of the lesson study group varies, it is normal for pre-service teachers to be involved in some teaching as well as observing.

Drawing on many accounts of mathematics lesson study in ITE (e.g. Corcoran and Pepperell 2011; Elipane 2011; Fernandez and 
Zilliox 2011; Gunnarsdóttir and Pálsdóttir 2011; Rasmussen 2016), we now address three aspects of implementing and sustaining mathematics lesson study in ITE which have been found to be particularly important in the English context.

\subsection{Productive partnership between HEI and school}

Successful lesson study in ITE depends on a productive partnership between the university-based teacher educator and the host school (Baldry and Foster, in press). All pre-service teachers undertake at least 24 weeks of teaching placements, where they are assigned an experienced teacher as their mentor to oversee and assess their progress. If pre-service teachers undertake lesson study, it is usually conducted during the placements. In these circumstances, the cooperation, if not the active involvement, of the school-based mentor is required. Pre-service teachers occupy a position in between HEI and school, and may sometimes need to mediate aspects of the process between their university tutor and their school-based mentor (see Baldry and Foster, in press). This 'boundary crossing' can prove a challenge, as reported by Tsui and Law (2007) in a study of trainee teachers of English in Hong Kong.

The current ITE landscape in England is currently experiencing a shift from HEI-based routes to school-based ones. Political rhetoric emphasises the practical knowledge that practising teachers possess, and identifies schools as the best place to learn to teach; conversely, university ITE courses are portrayed as being dominated by ideology and dogma and as taking negative stances on politically-promoted programmes and emphases. However, this negative view of what universities have to offer is not universally accepted, and many preservice teachers and schools are highly supportive of the role of university education departments and the experience and expertise that mathematics education tutors bring. Nevertheless, it is important to consider where power relationships among university tutors, in-service teachers (such as school-based mentors) and pre-service teachers may place constraints on how lesson study may be enacted in ITE. One particularly important aspect in this regard is the role of the 'knowledgeable other' (KO), which we discuss in the next 
section.

It is usual for the idea of embarking on mathematics lesson study in ITE to originate with the HEI, and thus there can be an issue of ownership, in which lesson study may appear to be 'done to' the preservice teacher and school-based mentor by the HEI. Ideally, lesson study would be seen as a supportive vehicle for the pre-service teacher's development and one to which the mentor can make a powerful contribution. However, in some models there is an expectation that the mentors teach a research lesson, a process that mentors may find uncomfortable, particularly if they link observation to teacher evaluation. Moreover, there are likely to be constraints imposed by the HEI concerning when and how the lesson study is carried out, resulting in a danger that the school, and perhaps pre-service teachers, comply in a reluctant or uninterested way, merely in order to meet course requirements. When schools are reluctant to engage, it is likely that the process will be of far less value to all parties, and may indeed be 'lesson study' only by name. In this case, the process may often default to more familiar and accepted forms of mutual lesson observation and evaluative feedback, which focus on 'how the teacher did' and 'what they could do to improve'.

Power imbalances between a pre-service teacher and a schoolbased mentor can also be a hindrance to effective lesson study. In this case, we see the lesson study process itself as holding a possible solution. Archer (2016), writing about power imbalances between pre-service teachers and mentors, found that lesson study: could break barriers established by positions of power and afford trainee teachers an opportunity to see themselves as experts whose power comes from their knowledge and reflections on their plans and from having been able to observe and reflect on children's work (p. 17)

Although carrying out mathematics lesson study in ITE may be complicated and 'messy' (Parks 2008), the structure of lesson study, when done in an appropriate way, can be effective in focusing all participants' attention onto school students' learning. This allows everyone's contribution - whether university tutor, school-based mentor or pre-service teacher - to be valued. Although pre-service teachers will naturally have more limited pedagogical knowledge than other participants, they may be good observers of what takes place in the classroom. Indeed, they may be able to approach this task with greater neutrality and objectivity, having less prior 
experience of students and classrooms to colour their perceptions. Moreover, the pre-service teachers may have had a good amount of induction into lesson study from their university tutors, and therefore can bring that expertise into the school setting, increasing what they may be perceived to have to offer to the process. Burroughs and Luebeck (2010) found that pre-service teachers could engage productively in lesson study alongside in-service teachers. Although they found tasks such as anticipating student responses to mathematics tasks difficult, the authors report that in-service teachers also did, and the authors concluded that this should not be seen as a serious limitation.

HEI-based routes for ITE, in which pre-service teachers spend a considerable portion of the year in block school placements, devote considerable attention to seeking to bring theory and practice together productively for the pre-service teachers. Fernández (2005) found that micro-teaching lesson study helped pre-service mathematics teachers to make links between theory and practice, and lesson study, with its emphasis on a 'research' lesson, can be a powerful way of linking theory to practice for pre-service teachers (Gunnarsdóttir and Pálsdóttir 2011). However, Bjuland and Mosvold (2015) found that a mathematics lesson study in Norway with preservice teachers ran into difficulties when the pre-service teachers did not focus in their observations on their students' learning. Moreover, reporting on lesson study undertaken by pre-service teachers in Spain, Angelini and Álvarez (2018) argued that the evaluation of student learning needed further development. Therefore, if the lesson-study process is to be as valuable as possible, we would underline the centrality of having a clear focus on student learning.

Theoretical perspectives play an integral part in planning and interpreting student learning, and HEIs are well placed to support preservice teachers with these. This could be a way of levelling power relations, because, for lesson study to be effective, planning and post-lesson discussion must involve more than drawing on existing professional experience. When collaboratively planning the research lesson, some participants may be better placed to predict student learning for each stage of the lesson, but such predictions are shared by all members of the planning group. With every participant focused on capturing student responses, about which none of them will 
have detailed prior knowledge, the privilege of prior experience is reduced.

\subsection{The locus of pedagogical knowledge}

A central aspect of mathematics lesson study as traditionally practised in Japan is the involvement of a 'knowledgeable other' (KO), an experienced in-service teacher or mathematics educator from outside the immediate setting who provides extensive expert commentary following the research lesson. Prestigious KOs draw large crowds of teachers to high-profile lesson study events in Japan, and the teachers' collective learning through the expert comments is frequently seen as the highlight of the entire process (Wake et al. 2016). In the model of mathematics ITE lesson study under consideration here, where there is only a small number of pre-service teachers (perhaps just one), together with their school-based mentor or university tutor, it is not practicable to bring in an external KO. This raises the question of how best to address the issue of pedagogical knowledge and how it might be developed within ITE lesson study.

Although unnecessary in Japan, since teachers are already very familiar with lesson study as a way of working, outside Japan a KO will also need to bring some expertise about the mechanics of orchestrating a lesson study. To this end, the $\mathrm{KO}$ may additionally be involved in the lesson planning stage, helping in-service teachers to collaborate and to raise the level of their planning beyond what they may be accustomed to. This can be helpful in facilitating a more beneficial research lesson for everyone and increasing the likelihood of positive early experiences of lesson study that all participants are then more likely to want to repeat (Wake et al. 2016). This adaptation of the traditional role of the KO seems warranted in these cases by the need in countries less familiar with lesson study than Japan for teachers to be inducted into this model of professional development.

For practical reasons, many models of lesson study in England do not attempt to incorporate a $\mathrm{KO}$ at all, since it can be too difficult and expensive to acquire the services of a suitable individual. 
However, if groups of teachers are not merely to re-circulate their prior views and perspectives, and are to gain new pedagogical insights, it seems necessary to consider how this might take place. Within ITE settings, it could be that the university tutor could offer this alternative perspective, even if not with the same level of expertise as in Japan. Often, in-service teachers will have limited knowledge of lesson study, whereas for preservice teachers this will probably be addressed by sessions at the university, which outline how the process should operate. Written materials can be passed to the school, and training sessions may be run to support mentors' and other participating in-service teachers' understanding of the purposes and practices of lesson study. It is clear that in mathematics ITE lesson study the participating in-service teacher, such as a school-based mentor, and/or the HEI tutor, bring considerable mathematics pedagogical expertise. However, it is much more difficult to address the mathematics pedagogical knowledge needed for fruitful post-lesson discussion (Foster et al. 2014).

The pre-existing knowledge and habits of in-service teachers may not easily lend themselves to a lesson-study approach, resulting in them falling back on models of lesson observation that focus on attempting to evaluate the quality of the teaching and offering advice for future lessons. Additionally, if lesson study is undertaken by a pre-service teacher and their school-based mentor, evaluative approaches may well have become the normal mode of operation, and it will be difficult for both of them to suspend this for the research lesson and resist treating the research lesson like every other lesson (Cajkler and Wood 2016b). We recognise that this entails a major shift in behaviour on the part of both mentor and pre-service teacher. This can be particularly difficult if in the mentor's other school roles (e.g., as mathematics department subject leader or member of senior leadership team) highly evaluative lesson observations are expected. Nevertheless, there is great potential in the pre-service teacher and mentor working together to modify their practice in this way (Cajkler and Wood 2015). For lesson study undertaken with university tutors working on ITE courses there may be similar issues, as making evaluative judgments of the teaching of pre-service teachers is an assessment requirement.

We believe that there is no 'quick fix' for the role of 
mathematics pedagogical knowledge in ITE lesson study, but we see considerable benefits in a rigorous observation focus on the students, rather than the teacher, in which all participants are encouraged to make detailed notes concerning what the students actually did and said, perhaps supplemented by photographs of the students' writing. In this way, the post-lesson discussion can be dominated by accounts of what students did and said, rather than more subjective, high-inference accounts for (Mason 2001) what was happening, especially when this is construed in terms of the teacher's actions.

In their study, Bjuland and Mosvold (2015) found that some preservice teachers in their first year of a four-year undergraduate teacher education course experienced difficulty in the implementation of lesson study, which was attributed to their inexperience of mathematics pedagogy. However, experience alone appears not to be the critical factor; Amador and Weiland (2015) found that preservice teachers' observations in lessons were more likely to include features of students' mathematical thinking than was the case for more experienced in-service teachers and university tutors. Therefore, if pre-service teachers can be successfully inducted into lessonstudy practices during their ITE course, then more constructive observation habits may be engendered that could persist into their teaching career.

\subsection{Lesson-study cycle}

Some variant of the lesson-study cycle presented in Figure 1 is typically used to characterise the chief features of the lesson-study approach (e.g. Cajkler and Wood 2016a; Dudley 2014a). In the normal course of their school placements, pre-service teachers in England are expected to write lesson plans and evaluations for each lesson that they teach, all of which is overseen by their school-based mentor. Thus, to pre-service teachers and their school-based mentors, the lesson-study cycle may sound superficially similar to their normal practice. Whilst it has been estimated that 10 percent of schools in England are involved in lesson-study projects (Dudley 2015), it is still not common practice for most teachers. So, there are limited points of reference to contrast lesson study with establish practice, 
and thereby discern critical features of the process. However, when implemented as intended, lesson study has important differences (Cajkler and Wood 2015), as we now consider.

\subsubsection{Planning the research lesson}

The adoption of lesson study in England appears to have brought with it a considerable compression in the time and scope of the planning phase compared with normal practice in Japan. Traditional Japanese lesson study usually takes place over a cycle of up to two years, with an overarching research theme derived from wider institutional priorities and shared beyond individual teams (Fujii, 2014). In contrast, within ITE programmes in England, timescales are far shorter - often just a few weeks - and lesson topics are usually selected pragmatically, based on those that the teachers were due to teach anyway. Kyouzai kenkyuu, the interrogation of relevant research and in-depth study of teaching materials, has been highlighted as one of the features of lesson study that has been 'lost in translation' when lesson study has been adopted outside of Japan (Takahashi and McDougal 2016, p.514). There is some evidence that theoretical frameworks that underpin lesson plans are less well articulated in English settings, if present at all (Cajkler and Wood 2016a; Larssen et al. 2018), leading to collaborative planning being more reliant on existing professional knowledge than drawing on wider research. In addition, typical English classroom resources (like those used in the US) are often of low pedagogical and mathematical quality, and their design may impede the planning process in the context of lesson study (Takahashi and McDougal, 2016). However, with the growing awareness of how lesson study can be adapted in different cultural contexts (e.g. Fujii 2014), ITE courses should be better situated to draw together the strands of research, resources and mathematics pedagogy into the planning phase of effective lesson-study projects.

In England, the tradition is for school departments to write curriculum plans ('schemes of work' or 'schemes of learning') that outline the topics that are to be taught, and when, but teachers individually plan the lessons for their own classes, and extensive periods of 
collaborative planning are relatively uncommon. In 2016, as one mechanism for reducing teachers' workload, the UK government published guidance to schools outlining the expectation that collaborative planning in schools should become standard practice (DfE 2016). Consequently, as with other aspects of lesson study, engagement in collaborative planning may be both a challenge and an opportunity for pre-service teachers. They may enter school environments where collaborative planning is not established practice, and in-service teachers may struggle to commit sufficient time to the process. However, with appropriate support, pre-service teachers could have both the time and resources to develop collaborative practices, which would both enhance their professional development as well as provide an opportunity to bring 'expertise' to lesson study projects in schools. Lesson study scaffolds a collaborative, interactive approach which may enhance a school's approach to teaching mathematics.

\subsubsection{Teaching the research lesson}

Where mathematics pre-service teachers in England are involved in some kind of lesson study, it is common for the pre-service teacher to both teach and observe research lessons. The composition of lesson-study teams within ITE varies, with almost all combinations of pre-service teachers, university tutors and in-service teachers (who may or may not be the school-based mentor) occurring, and with varying levels of involvement. For example, a pre-service teacher and school-based mentor may work as a pair, or several pre-service teachers may work together, with the in-service teachers taking on different roles, from observer or teacher of the lesson to a fully-integrated member of the lesson-study team. Within these diverse approaches, how participants consider ownership of the research lesson will vary. For example, Archer (2016) found that pre-service teachers who planned the research lessons felt entitled to hold the in-service teachers to account when the in-service teacher taught the research lesson but deviated from the lesson plan. Developing a shared responsibility for designing and understanding the lesson plans can be enhanced if the decision of who teaches the research lesson is 
made after the planning is completed, and is perhaps decided at random (Forsythe and Baldry 2017). The notion of repeated cycles of lesson study has been advocated by some in the UK (e.g. Dudley 2014a); if featured in ITE lesson study, then the timescale for this tends to be condensed to as little as a week, due to the structural constraints of courses. The notion of 're-teaching' the 'same' lesson to a different class (e.g. Cajkler and Wood 2016a), which does not appear to be central to Japanese lesson study, can be problematic if it leads participants to infer that the main goal of lesson study is to 'perfect' a lesson plan, rather than to develop a deeper understanding of teaching and learning (Takahashi and McDougal 2016).

\subsubsection{Observation of the research lesson}

The observation of several case-study students, chosen in advance, rather than the whole class or the teacher, is an integral part of lesson study, and yet something that pre-service teachers, and often their school-based mentors, find difficult. Transmission teaching approaches (Askew et al., 1997), which are common in mathematics lessons in England, may make deep learning hard to discern. Problem solving combined with in-depth classroom discussion, a central feature of mathematics teaching in Japan, is not a routine part of many mathematics lessons in schools in England. More commonly here, the teacher models a single method, followed by individual students' practice of very similar questions. In observations of such lessons, observers may be looking for clear explanations from the teacher and evidence of students completing large numbers of questions successfully. The usual focus for lesson observations in England is a judgment of the teacher's performance, and it can be very difficult to move away from this (Archer 2016). Consequently, clear prior direction is required to ensure that sufficiently detailed appropriate data is collected from the research lesson to enable productive conversations in the post-lesson discussion.

Both pre-service and in-service teachers require considerable coaching in how to make such observations about students' behaviours, rather than generalised evaluative judgments, such as "they were really engaged", "they got on really well with their work" or 
"they had a really good discussion". Highlighting beforehand that such comments are likely to be less useful can be helpful in enabling participants to raise the level of their observations, but this still takes time to achieve. A widely used pro-forma for lesson-study observations is the annotation of a lesson plan that includes anticipated student responses (Dudley 2014a), though, in this case, the quality of observations may be limited by the quality of the planning. We have found that making detailed notes about observed behaviours is a skill that pre-service teachers can develop quickly and early in ITE courses. This can allow them to capture sufficient data for productive discussions about the interpretation of those behaviours in terms of learning at a later stage. One additional source of information advocated by Dudley (2014a) is to interview the case-study students. While taking additional time, and making further demands on the students and teacher, this can provide further insights into students' learning and emphasise the central nature of the students to the lesson-study process.

\subsubsection{Post-lesson discussion}

The post-lesson discussion is the culmination of Japanese lesson study, a central role being played by a knowledgeable other $(\mathrm{KO})$, who offers an expert commentary on what has taken place during the research lesson and summarises what may be learned from that (Takahashi and McDougal 2016). In England, this is another area where teachers' and pre-service teachers' day-to-day experiences may detract from the purposes of lesson study. In normal practice in England, discussions about an observed lesson tend to be highly evaluative judgements about the teacher's performance rather than focused on student learning (Noyes 2013). Moreover, the observer is unlikely to have the experience of both pedagogy and lesson study that would be normal in Japan, meaning that there is a danger that the post-lesson discussion can fail to interrogate the available data about student learning to the full benefit of the participants.

When the post-lesson discussion includes experienced in-service teachers and university tutors, matters may be improved, but this is not necessarily the case, as there are some indications that these 
participants may also be likely to shift the focus away from student learning (Amador and Weiland 2015). When there are repeated cycles of lesson study, the post-lesson discussion can sometimes focus unhelpfully on proposed changes rather than on developing an understanding of teaching and learning from the observed lesson. However, case studies have also demonstrated that pre-service teachers can observe in sufficient detail to start discussing what the various behaviours observed may indicate about student reasoning (Forsythe and Baldry 2017). Forsythe and Baldry (2017) found that whilst discussions often drifted towards classroom organisation and teaching, tight discussion protocols sometimes allowed productive discussions to be extended. With teacher performance so central in English schools and ITE courses, mathematics lesson study is both difficult to enact successfully here but also has great potential to bring new perspectives to both in-service and pre-service teachers.

\section{Key features of mathematics lesson study for ITE in England}

Now that lesson study has been adopted and adapted in several countries, recent research has looked at how the approach can be most effectively deployed in different cultural contexts (e.g. Takahashi and McDougal 2016). Drawing on the research literature discussed in section 2, and our own experiences of lesson study in ITE, here we highlight how key features of mathematics lesson study may be enacted successfully in English ITE contexts.

\subsection{Partnership}

Productive relationships need to be developed between all parties if lesson study is to be effective (Baldry and Foster in press). University tutors are often best placed to introduce lesson study into ITE courses, with the understanding that the schools' contexts are, however, critical. For example, we have seen that highlighting the fact that in Japan all teachers engage and expect to learn from the 
process has facilitated greater participation by school-based mentors and in-service teachers in England, some of whom had expressed unease about an unfamiliar process.

\subsection{Knowledgeable others}

In England there are two facets to the role of a KO: one related to the lesson study process itself and one related to mathematics pedagogy. As lesson study in not established practice in England, the university tutor usually takes responsibility to act as the 'expert' in lesson study, even though they themselves may not have participated in lesson study in schools. Within mathematics ITE lesson study, if university tutors do not work directly with schools, their design of introductory materials and support processes still allows them to fulfil this function of a KO. Mathematics pedagogy is more complex, as university tutors are likely to bring mathematics education research expertise, while in-service teachers tend to contribute situated and professional knowledge, and these may be seen as being in tension, with neither party typically having the expertise that the designation of KO would bring in Japan.

However, the lesson-study KO role provides a powerful mechanism for considering mathematics pedagogy in more detail. For example, in our local lesson-study projects, the use of wider research in the planning stage is promoted through university tutors working directly with pre-service teachers and by providing access to research findings for school-based mentors. As discussed below, at each stage of the lesson-study cycle, structures and processes can be instigated that allow expertise from outside the immediate lessonstudy group to be drawn on, and indeed this may be from more than one person (figure 2).

We have also seen the professional capital of school-based mentors enhanced through participation in lesson study, which gradually leads to the growth of KOs in schools. For example, one group of local schools participated in lesson study with pre-service teachers for four years; over that time some school-based mentors extended the use of lesson study to their own department's practice. Use of lesson study in ITE thus contributes to a stronger focus on pedagogy that 
can lead to wider impact on in-service teachers.

\subsection{Structure}

If there is more than one pre-service teacher involved in the lesson study, then engagement with planning may be more productive if the choice of who will teach the research lesson takes place after the planning is completed, and perhaps randomly. We have found that this encourages all participants to be fully invested in the planning process, since each person needs to be comfortable with what is to be taught and how.

The notion that the research lesson needs to be repeated has some traction in England, and so it is worth clearly articulating that this is not a requirement. If more than one research lesson is going to be undertaken, then subsequent lessons do not necessarily need to use the same plan; if the next lesson is based on the same topic being taught to a different class, then care is needed to ensure that the notion of 'perfecting' a lesson plan is not taken to be the central purpose, as this can detract from a focus on students' learning of mathematics.

Following a research lesson, a document may be produced outlining the key learning points from the lesson for the participants, and this could be more widely distributed among other pre-service teachers on the ITE course and also among the rest of the mathematics department in the school.

\subsection{Research question}

The goal of mathematics lesson study is to develop greater understanding of teaching and learning mathematics. Consequently, when planning the research lesson, specifying a clear research question can help to focus the planning and the observation on one small aspect of students' learning of mathematics. In this way, participants may be able to avoid vague, general remarks that do not advance the interrogation of student learning. We have found that it can take a 
number of iterations before pre-service and in-service teachers are able to articulate a specific research question that moves beyond matters of 'engagement' or 'discussion', and providing examples of productive research questions has been very helpful. Additionally, mathematics lessons with dual goals, that include ways of working as well as content, can be richer and particularly useful for research lessons; for instance, we have offered "for students to make and test conjectures" as well as "for students to develop an understanding of the gradient and intercept parameters in straight lines" as examples. A topic that is considered 'hard to teach' may benefit most from the intense scrutiny that is possible in lesson study; we have used the term 'learning challenge' as a prompt for this and as a reminder to focus on learning, and not engagement or behaviour (figure 2, section 1).

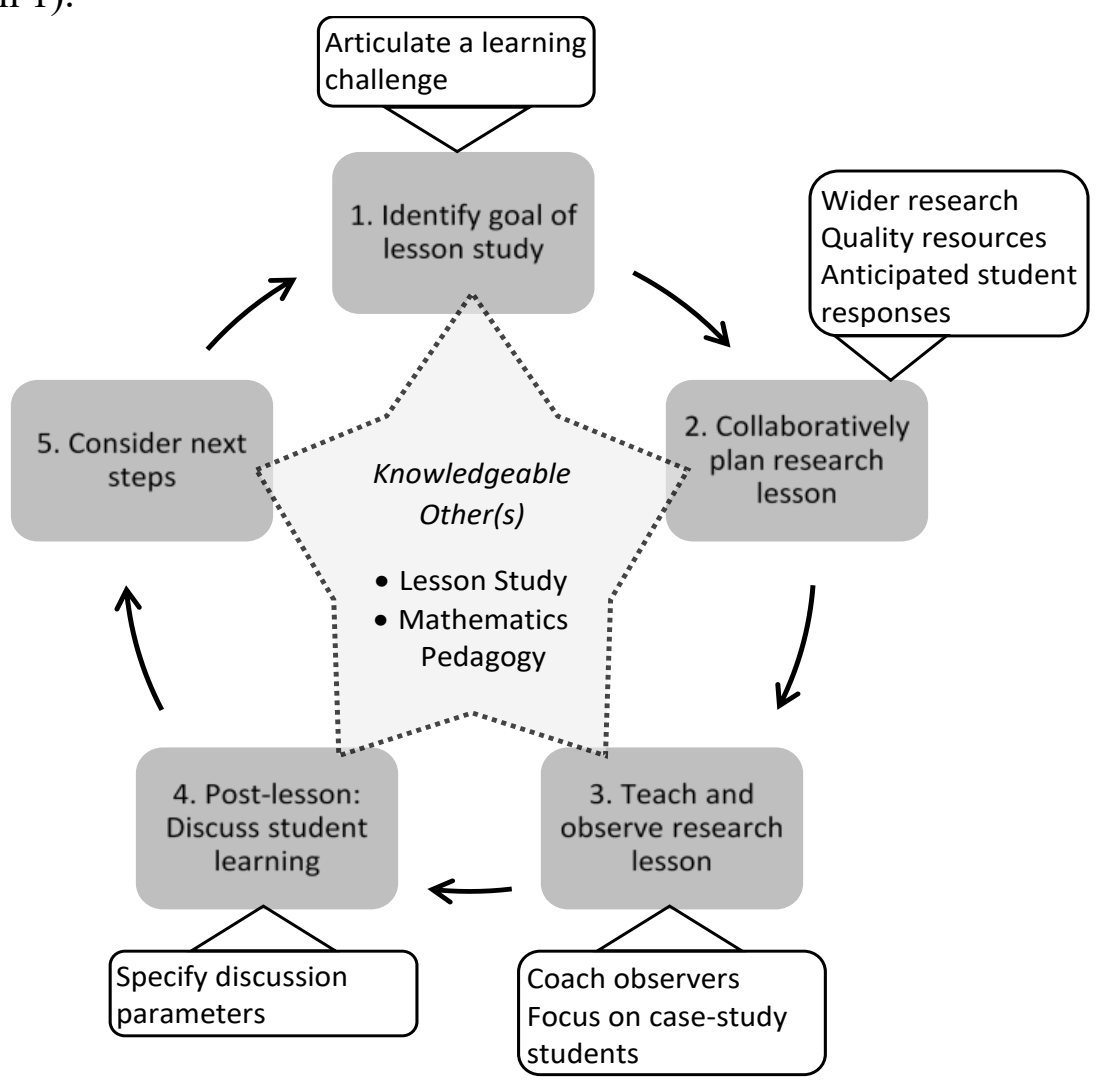

Fig. 2 Key features of a lesson study for mathematics ITE. 


\subsection{Collaborative planning}

Pre-service teachers generally need considerable support in completing detailed lesson plans that go beyond the procedural aspects of what the students are going to do. And, indeed, all participants may be unfamiliar with collaborative planning, including appreciating the amount of time needed. Therefore, providing access to wider research and well-considered resources should be facilitated - a role usually performed by the university tutor (figure 2 , section 2 ). We have found it highly beneficial to specify that all those involved in planning should complete all the mathematical tasks for themselves, considering possible alternative solution strategies and representations and seeking to anticipate how students may respond to the task. This has not only helped participants to build an understanding of how learning may be 'visible' as students engage in the tasks, it also provided a learning focus for discussion in collaborative planning meetings. Carrying this out 'as a student might' can be of considerable benefit, allowing teachers to consider likely errors and misconceptions and how the teacher will address these (figure 2, section 2). This articulation of anticipated student responses - and planning for how to respond to them - is a critical part of assessing and developing understanding of student reasoning, as well as providing a focus for the lesson observation (Wake et al. 2016).

\subsection{Research lessons}

We have often found it necessary to reinforce the message that the observation focus is to be students and their engagement in mathematics tasks, rather than the teacher's 'performance'. In order to be in a position to collect sufficiently detailed information, a maximum of three case-study students may be selected per observer, and, as detailed observation notes are required, all observers should be inducted into what and how to observe (figure 2, section 3). As with the research questions, it can take time for participants to move away from general statements about student engagement and evaluative judgments. Modelling the process through the use of either a live lesson or a video recording of students engaged in mathematical 
activities can be effective. Dudley (2014b) advocates the use of lesson plans with space next to anticipated student responses as an observation pro forma; this can be an effective way of drawing the attention of the observer to the specific actions of the students. If casestudy students are interviewed, stimulated recall (where students are asked about how and why they completed particular tasks) may produce more useful information about learning than more general interviews.

\subsection{Post-lesson discussions}

In our experience, clear protocols are needed in order to steer participants towards sharing detailed descriptions of particular incidents, followed by the interpretation of these descriptions in terms of those individual students' mathematical reasoning (figure 2, section 4). The inclusion of a 'stop' protocol if classroom organisation, evaluation of teaching or deficit models of student reasoning appear in the discussion can be particularly useful. As suggested above, it may be helpful to list in advance examples of the kinds of statements which are likely to be less helpful, such as, "They really got on well with the task" and why these kinds of comments are unlikely to contribute to a productive post-lesson discussion. When student errors were discussed, we have found it powerful to have reminders that any comments about students 'not understanding...' could be reversed to articulate how the students might be reasoning; the idea that students are attempting to make sense of mathematics appears to shift some discussions away from student deficit models and towards learning. Time can be a limiting factor for some participants; we have seen that giving permission for part of the lesson to be discussed in detail, rather than attempting to cover the whole lesson, has made better use of limited time.

\section{Conclusion}

The challenge of modifying Japanese lesson study so that it both 
adapts to a different cultural context while at the same time challenges aspects of that context, is considerable. Introducing lesson study in a new context or country means challenging some cultural traditions, which takes time and can be difficult (Stigler and Hiebert 1999; Wake et al. 2016). Features of the educational landscape in England present considerable challenges to the kind of approaches adopted in Japan. The constraints are tighter still for mathematics and ITE, and yet the potential benefits of even a highly-constrained form of lesson study are considerable, both for pre-service teachers and for the schools in which they are placed for teaching practice.

Lesson study has been successfully operationalised in our context by making numerous adaptations and compromises. Important among these have been the acceptance of a shorter time scale and the absence of a well-defined knowledgeable other. Typical lesson observation practices in schools in England need considerable modification for productive lesson study, as do approaches to lesson planning. However, these challenges are highly productive in terms of developing pre-service teachers' practices and have enormous potential to support their pedagogical development, as we have described. Inducting future teachers into lesson-study practices, and facilitating first experiences of lesson study which are positive and clearly beneficial to all, may prepare pre-service teachers for future careers in which they value such ways of working and perhaps bring them into their future schools.

Where productive partnerships between university and school can be engineered, where time can be found for collaborative lesson planning that focuses on a clear research question that also forms the basis for detailed lesson observation relating to student learning of mathematics, and where a tight protocol for post-lesson discussions is in place, the chances for productive mathematics lesson study in ITE are maximised.

\section{Acknowledgement}

We would like to thank Professor Wasyl Cajkler for very helpful comments on an early draft of this chapter and Dr Sue Forsythe for her 
insights from her work with mathematics ITE pre-service teachers. We would also like to thank the anonymous reviewers for their comments on this chapter.

\section{References}

Amador, J., \& Weiland, I. (2015). What preservice teachers and knowledgeable others professionally notice during lesson study. The Teacher Educator, 50(2), 109-126.

Angelini, M. L., \& Álvarez, N. (2018). Spreading lesson study in pre-service teacher instruction. International Journal for Lesson and Learning Studies, 7(1), 23-36. doi: doi:10.1108/IJLLS-03-2017-0016

Archer, R. (2016). Lesson study in initial teacher education: students' positioning analysed through the lens of Figured Worlds. Paper presented at the British Society for Research into Learning Mathematics.

Askew, M., Brown, M., Rhodes, V., Wiliam, D., \& Johnson, D. (1997). Effective Teachers of Numeracy: Report of a study carried out for the Teacher Training Agency. London: King's College, University of London.

Baldry, F., \& Foster, C (in press). Lesson study partnerships in initial teacher education. In P. Wood \& D. Larssen (Eds.), Lesson Study in Initial Teacher Education. A Critical Perspective. London: Emerald

Bjuland, R., \& Mosvold, R. (2015). Lesson study in teacher education: Learning from a challenging case. Teaching and Teacher Education, 52, 83-90.

Burroughs, E. A., \& Luebeck, J. L. (2010). Pre-service teachers in mathematics lesson study. The Mathematics Enthusiast, 7(2), 391-400.

Cajkler, W., \& Wood, P. (2015). Lesson Study in initial teacher education. In P. Dudley (Ed.), Lesson Study : Professional learning for our time (1st ed.. ed.). London: Taylor \& Francis Group.

Cajkler, W., \& Wood, P. (2016a). Adapting 'lesson study' to investigate classroom pedagogy in initial teacher education: what student-teachers think. Cambridge Journal of Education, 46(1), 1-18.

Cajkler, W., \& Wood, P. (2016b). Mentors and student-teachers "lesson studying" in initial teacher education. International Journal for Lesson and Learning Studies, 5(2), 84-98. doi: doi:10.1108/IJLLS-04-2015-0015

Corcoran, D., \& Pepperell, S. (2011). Learning to teach mathematics using lesson study. In R. K. Rowland T. (Ed.), Mathematical knowledge in teaching (Vol. 50, pp. 213-230). Dordrecht: Springer.

DfE. (2016). Eliminating unnecessary workload around planning and teaching resourcesp. London: Crown Retrieved from https://www.gov.uk/government/publications/reducing-teacher-workload-planning-and-resources-group-report.

Dudley, P. (2014a). How Lesson Study works and why it creates excellent learning and teaching. Lesson Study, 1.

Dudley, P. (2014b). Lesson Study Handbook (revised).

Dudley, P. (2015). Lesson Study : Professional learning for our time (1st ed.. ed.). London: Taylor \& Francis Group.

Elipane, L. (2011). Incorporating lesson study in pre-service mathematics teachers education. Proceedings of the 35th Conference of the International Group of the Psychology of Mathematics Education, 1, 305-312. 
Fernandez, C., \& Yoshida, M. (2012). Lesson study: A Japanese approach to improving mathematics teaching and learning: Routledge.

Fernández, M. L. (2005). Exploring “lesson study” in teacher preparation. Paper presented at the Proceedings of the 29th Conference of the International Group for the Psychology of Mathematics Education.

Fernandez, M. L., \& Zilliox, J. (2011). Investigating approaches to lesson study in prospective mathematics teacher education Lesson study research and practice in mathematics education (pp. 85-102): Springer.

Forsythe, S., \& Baldry, F. (2017). Developing effective Learning Circles: An account of how student teachers participated in a shared dialogue of a team teaching experience. Paper presented at the European Conference on Educational Research 2017, Copenhagen.

Fujii, T. (2014). Implementing Japanese Lesson Study in foreign countries: Misconceptions revealed. Mathematics Teacher Education \& Development.

Gunnarsdóttir, G. H., \& Pálsdóttir, G. (2011). Lesson study in teacher education: A tool to establish a learning community. Paper presented at the Proceedings of the Seventh Congress of the European Society for Research in Mathematics Education.

Larssen, D. L. S., Cajkler, W., Mosvold, R., Bjuland, R., Helgevold, N., Fauskanger, J., . . Norton, J. (2018). A literature review of lesson study in initial teacher education: Perspectives about learning and observation. International Journal for Lesson and Learning Studies, 7(1), 8-22.

Lewis, C. (2009). What is the nature of knowledge development in lesson study? Educational action research, 17(1), 95-110.

Noyes, A. (2013). The effective mathematics department: adding value and increasing participation? School Effectiveness and School Improvement, 24(1), 1-17. doi: 10.1080/09243453.2012.689145

Parks, A. N. (2008). Messy learning: Preservice teachers' lesson-study conversations about mathematics and students. Teaching and Teacher Education, 24(5), 1200-1216.

Rasmussen, K. (2016). Lesson study in prospective mathematics teacher education: didactic and paradidactic technology in the post-lesson reflection. Journal of Mathematics Teacher Education, 19(4), 301-324.

Stigler, J. W., \& Hiebert, J. (1999). The teaching gap: Best ideas from the world's teachers for improving education in the classroom. New York: Free Press.

Takahashi, A., \& McDougal, T. (2016). Collaborative lesson research: maximizing the impact of lesson study. ZDM, 48(4), 513-526. doi: 10.1007/s11858-015-0752-x

Wake, G., Swan, M., \& Foster, C. (2016). Professional learning through the collaborative design of problem-solving lessons. Journal of Mathematics Teacher Education, 19(2$3), 243-260$. 